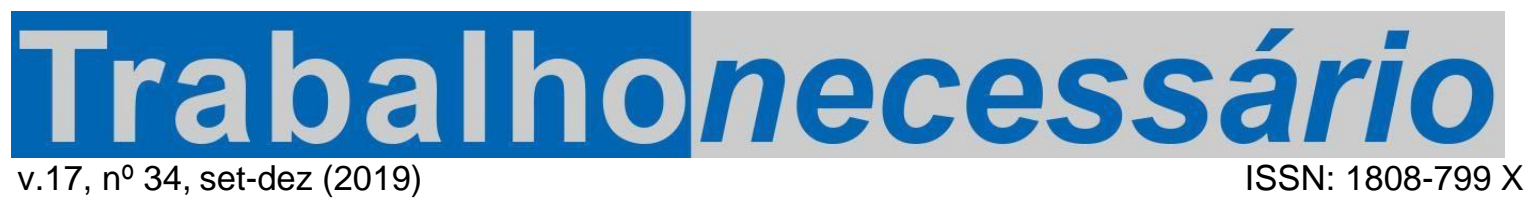

\title{
A UBERIZAÇÃO DO TRABALHO DOCENTE NO BRASIL: UMA TENDÊNCIA DE PRECARIZAÇÃO NO SÉCULO XXI'1
}

Amanda Moreira da Silva ${ }^{2}$

\section{Resumo}

Resultado de uma pesquisa recém-concluída, tendo como base o materialismo histórico dialético, o presente artigo identifica a uberização como uma tendência do trabalho no século XXI e busca analisar como isso se estende para os trabalhadores docentes do setor público. Destacou-se o impacto das condições contratuais de trabalho por tempo determinado, sob as quais os professores da educação básica estão inseridos, trazendo como protótipo uma forma de contratação existente na rede estadual de São Paulo e novas tentativas de uberização ocorridas em outras redes públicas brasileiras.

Palavras-chave: Trabalho Docente; Precarização; Uberização.

\section{LA UBERIZACIÒN DEL TRABAJO DOCENTE EN BRASIL: UNA TENDENCIA DE PRECARIZACIÓN EN EL SIGLO XXI}

\section{Resumen}

Resultado de una investigación recién completado, basado en el materialismo histórico dialéctico, el presente artículo identifica la uberización como una tendencia del trabajo en el siglo XXI y busca analizar cómo se extiende a los trabajadores docentes del sector público. Se destacó el impacto de las condiciones contractuales de trabajo por tiempo determinado, bajo las cuales los maestros de la educación básica están insertos, trayendo como prototipo una forma de contratación existente en la red estatal de São Paulo y nuevos intentos de uberización ocurridos en otras redes públicas brasileñas.

Palabras clave: Trabajo Docente; Precariedad; Uberización.

\section{THE UBERIZATION OF TEACHING WORK IN BRAZIL: A TREND OF PRECARIZATION IN THE $21^{\text {ST }}$ CENTURY}

\section{Abstract}

The result of a recently completed research, based on dialectical historical materialism, this article identifies uberization as a trend of work in the $21^{\text {st }}$ century and seeks to analyze how this extends to public sector teaching workers. It was highlighted the impact of contractual conditions of fixed-term work, under which teachers of basic education are inserted, bringing as prototype a form of contracting existing in the state network of São Paulo and new attempts of uberization occurred in other brazilian public networks.

Keyword: Teaching Work; Precariousness; Uberization.

\footnotetext{
1 Artigo recebido em 02/07/2019. Primeira Avaliação em 22/07/2019, Segunda Avaliação em 21/07/2019. Aprovado em 11/09/2019. Publicado em 27/09/2019. DOI: https://doi.org/10.22409/tn.17i34.p38053

2 Mestra e Doutora em Educação pela Universidade Federal do Rio de Janeiro. Professora da Universidade do Estado do Rio de Janeiro. E-mail: amandamoreira.uerj@gmail.com https://orcid.org/0000-0001-9416-0619
} 


\section{Introdução}

Em 2019, o desemprego no Brasil atingiu, em média, 12,7\% no primeiro trimestre e o número de pessoas em busca de trabalho no país chegou a 13,4 milhões (IBGE, 2019). Diante do desemprego e da inserção crescente de novos conceitos relaxadores do vínculo de emprego, cada vez mais trabalhadores se submetem aos contratos precários, sem garantias trabalhistas e com longas jornadas de trabalho.

São diversos tipos de contratação enquadradas nesses moldes, dentre elas um tipo muito crescente e que tem se alastrado em algumas cidades do país: aquela vinculada ao aplicativo Uber². Esta empresa tem atuação global, envolve milhões de trabalhadores e o seu formato tem a possibilidade de se generalizar pelas relações de

trabalho em diversos setores, inclusive na educação (e na educação pública), conforme será abordado neste artigo que trata especificamente do trabalho docente.

$O$ trabalho na Uber materializa a ideia de que o trabalhador tem que ir para o mercado de trabalho levando tudo, sendo responsável pela mercadoria que vai vender e pelo serviço que vai prestar. Trata-se de um novo passo na terceirização onde as

empresas desenvolvem mecanismos de transferência de custos e riscos não mais para empresas terceirizadas, mas para uma multidão de trabalhadores autônomos disponíveis, retirando suas garantias mínimas e ao mesmo tempo consolidando a sua

subordinação. Nesse tipo (ou ausência) de vínculo, as formas de controle são (aparentemente) pouco tangíveis, pois não há horário fixo de trabalho, o trabalhador não é um empregado e a empresa não é sua contratante.

O artigo é composto por duas partes. Inicialmente identificou-se a uberização como uma tendência do trabalho no século XXI, e, posteriormente, buscou-se analisar como isso se estende para os trabalhadores docentes do setor público. Para isso considerou-se 0 impacto das condições contratuais de trabalho por tempo determinado, sem plenos direitos, sob as quais os docentes de algumas redes públicas municipais e estaduais estão inseridos, o que faz com que estes sejam impedidos de vivenciarem uma vida laboral dotada de algum sentido.

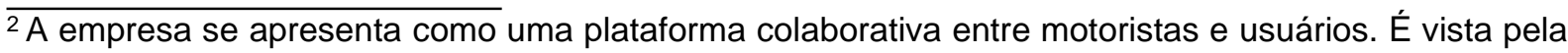
população que faz uso do serviço como democrática porque barateia o custo do transporte, mas na prática, o que ocorre com a entrada da empresa é uma devastação das conquistas de transporte público e a piora da mobilidade urbana com um número excessivo de transportes individuais de passageiros nas cidades em que existe o serviço.
} 
Tendo como método o materialismo histórico dialético, analisou-se um enorme campo de trabalho mal pago e com uma tendência de transformar o trabalho docente em trabalho intermitente, com professores sendo contratados de acordo com as necessidades eventuais do poder público e arcando com a transferência de custos e riscos. Assim, o presente artigo tratou de uma forma de contratação existente na rede pública estadual de São Paulo e de tentativas de uberização em outras redes públicas de educação básica pelo país, se mostrando como uma tendência para o trabalho docente no século XXI.

A esse contexto adensam-se as políticas governamentais em curso desde os anos 1990, as reformas educacionais e a privatização acentuada que vêm contribuindo para aumentar a flexibilização do trabalho docente por meio de formas de contratação precárias com benefícios e salários inferiores, que foram se infiltrando furtivamente nas redes públicas (SILVA, 2017, 2018), o que acabou ampliando o contingente de trabalhadores sem direitos, diferentemente do que caracteriza a relação salarial segura presente no setor público.

\section{A uberização do trabalho como tendência no século XXI}

Tom Slee, economista britânico-canadense, autor de Uberização: a nova onda do trabalho tornou-se um dos principais estudiosos do problema gerado pelas corporações digitais. No livro, ele traz de forma ilustrativa, e apoiando-se numa sólida base empírica, as discussões relacionadas à "Economia do Compartilhamento3", demonstrando de que forma isso se intensificou após o início das operações da Uber em diversos países, e gerando consequências sociais desastrosas. Além disso, o autor desmistifica a aura do uso parcimonioso dos recursos ${ }^{4} \mathrm{e}$ a utopia cooperativista com que a Economia do Compartilhamento foi encarada em sua fase inicial,

\footnotetext{
${ }^{3} \mathrm{~A}$ Economia do Compartilhamento, às vezes descrita com outros nomes como: consumo colaborativo, economia em rede, plataformas igual-para-igual, economia dos bicos, economia da viração, economia sob demanda etc., é uma onda de novos negócios que usam a internet para conectar consumidores com provedores de serviço para trocas no mundo físico, como aluguéis imobiliários de curta duração, viagens de carro, realização de tarefas domésticas, entre outras.

${ }^{4}$ As promessas iniciais da Uber e da Economia do Compartilhamento como um todo era ser uma alternativa sustentável para o comércio de grande circulação, diminuindo os impactos ambientais no planeta. "Por que não usar a Uber em vez de comprar um carro? Podemos priorizar o acesso em detrimento da propriedade, e nos livrarmos de um consumismo ao qual muitos de nós nos sentimos presos" (SLEE, 2017, p.23). Obviamente, isso não se materializou, ao contrário, conforme bem demonstrou o autor "a economia do compartilhamento está propagando um livre mercado inóspito e desregulado" (SLEE, 2017, p.23).
} 
apresentando que o suposto compartilhamento deu lugar à formação de gigantes corporativos $^{5}$, acumulação de fortunas impressionantes, desregulamentação generalizada, perda de autonomia dos indivíduos, precarização do trabalho etc. Deste modo:

Muitas companhias da Economia do Compartilhamento estão dando fortuna a seus investidores e executivos e criando bons empregos para seus engenheiros de programação e marqueteiros, graças à remoção de proteções e garantias conquistadas após décadas de luta social, e graças à criação de formas de subemprego mais arriscadas e precárias para aqueles que de fato suam a camisa (SLEE, 2017, p.24).

O aplicativo Uber popularizou uma forma de contratação no mundo dos transportes individuais e tem se alastrado em alguns países, incluindo o Brasil, o que tem levado alguns pesquisadores brasileiros (POCHMANN, 2016; FONTES, 2017) à defesa de que a empresa Uber tornou-se uma chave para analisar as transformações contemporâneas do mundo do trabalho. "Seu enorme impacto já gerou novos termos, como a 'uberização das relações de trabalho' e um verbo, 'uberizar'” (FONTES, 2017, p.54).

Pochmann (2016) refere-se à "uberização" como a emergência de um novo padrão de organização do trabalho - após o fordismo e o toyotismo - caracterizado pela autonomização dos contratos de trabalho e que, dependendo da resistência dos movimentos contestatórios, pode se generalizar. "É o trabalhador negociando individualmente com o empregador a sua remuneração, seu tempo de trabalho, arcando com os custos do seu trabalho" (POCHMANN, 2016, p.17).

Com a uberização, há a eliminação do conceito de contratação por jornada, o salário se torna custo variável, pois ele só existe se de fato houver a realização daquele trabalho e as jornadas levam frequentemente ao uso das horas vagas para aumentar a renda. Neste tipo de relação, qualquer tempo disponibilizado pelo trabalhador é tempo de lucro. Como destaca Fontes (2017, p.58):

Para além do credenciamento e do localizador, não há controle direto próximo aos trabalhadores: apenas a pura necessidade deve movêlos ao trabalho. Não há jornada de trabalho combinada ou obrigatória, nem limites para ela, tampouco dias de repouso remunerado. Estes se sabem trabalhadores, mas não se consideram como tal, mas como

\footnotetext{
${ }^{5}$ O valor de mercado da Uber (mais de 64 bilhões de dólares em 2016, seis anos após a sua fundação) supera o da maior companhia de aluguel de veículos do planeta, além da Ford e General Motors; o do Airbnb iguala-se ao da maior cadeia internacional de hotéis (InternContinental) e, apesar de integrarem indústrias aparentemente prosaicas (táxis, aluguel de residências), os fundadores de cada uma são agora bilionários (SLEE, 2017; ABÍLIO, 2017).
} 
prestadores de um serviço casual, mesmo se movidos pela mais dramática necessidade. De fato, eles não têm um emprego, mas uma conexão direta de entrega do mais-valor aos proprietários capazes de Ihes impor um processo de produção de valor pré-estabelecido. Não são os poros do tempo livre que tais proprietários procuram obturar, como nos processos fabris, que realizam estrito controle do tempo de trabalho. Aqui, trata-se de lidar com novas escalas, ampliando o volume de valor, através de fornecedores massivos de mais-valor.

Ao tratar de algumas características da Uber, considerando que esta figura apenas como um exemplo, a autora afirma que a empresa detém, juntamente com outras grandes empresas ou proprietários: "a propriedade dos recursos sociais de produção". Ou seja,

[A] Uber não é proprietária direta das ferramentas e meios de produção (o automóvel, o celular), mas controla ferreamente a propriedade da capacidade de agenciar, de tornar viável a junção entre meios de produção, força de trabalho e mercado consumidor, sem intermediação de um "emprego" (FONTES, 2017, p.56).

Entusiastas da Uber atribuem o sucesso da empresa à sua tecnologia e eficiência em conectar passageiros e motoristas, mas essa visão ignora boa parte da história resgatada por Tom Slee:

O sucesso da Uber também se dá muito devido a evitar custos com seguro, impostos e inspeção veiculares, e em fornecer um serviço universalmente acessível. Sua habilidade em fornecer um serviço barato e eficiente para os consumidores vem da habilidade de operar em prejuízo enquanto persegue seu generosamente financiado caminho para o crescimento. O sucesso da Uber decorre de seu parasitismo nas cidades em que opera (SLEE, 2017, p.104).

Segundo Fontes (2017), trata-se de uma coligação íntima entre empresas de diversas áreas - a Google, os grandes bancos, montadoras de automóveis, numa das pontas mais concentradas da propriedade - que viabilizam o controle econômico do processo na parte que lhes interessa: o controle da extração, a captura do mais-valor em larga escala e de forma massiva no mundo inteiro. Assim,

[...] a defesa da propriedade intelectual da criação de um processo (a conexão) une-se estreitamente a investidores que, detentores de quantias de dinheiro monumentais, precisam transformá-las em capital, isto é, investi-las em processos de extração de valor. Tais investidores podem ser provenientes de setores variados: fundos de investimento de risco como Benchmark ou First Round Capital, grandes conglomerados financeiros, como Goldman Sachs ou empresas como Amazon ou Google, sem falar em acordos com operadoras de cartão de crédito, com montadoras ou empresas de aluguéis de automóveis (FONTES, 2017, p.56). 
De acordo com a autora, somente a escala atingida pela "propriedade dos recursos sociais de produção" permite acoplar uma plataforma de busca a uma tecnologia móvel de cartão de crédito e a um localizador, que asseguram a estreita dependência do trabalhador. Afinal, do cartão - de onde são extraídos diretamente entre 20 e $25 \%$ do valor gerado pelo trabalho - depende sua própria remuneração e o localizador denuncia todos os percursos do trabalhador, uma vez acionado o celular (conexão principal). Assim "a taxa de extração de valor é férrea, assim como o regime de trabalho" (FONTES, 2017, p.56). Deste modo:

[...] há uma centralização absoluta e internacional do comando sobre os trabalhadores e redução dos custos do processo de valorização do valor. Aparentemente, há apenas um aplicativo de computador a conectar motoristas e usuários. Isso é falso, pois, entre eles, há um credenciamento (para os motoristas e usuários), um cartão de crédito e um rastreador do movimento do motorista, todos totalmente arbitrários e autocráticos. Somente envolvem direitos para os proprietários do capital, escassas garantias para os usuários e nenhum direito para o trabalhador, salvo o de receber parcela do que produziu. Redução de custos não quer dizer sua inexistência: a centralização a esse nível exige intensa coordenação internacional da administração e gestão, além da partilha do lucro entre os demais proprietários dos recursos sociais de produção (FONTES, 2017, p.57, grifos da autora).

A empresa Uber é um exemplo de precarização do trabalho, de retirada de direitos, e faz questão de ignorar as condições de vida dos trabalhadores, "assegurando-se um custo próximo de zero para maquinaria, matéria-prima (combustíveis, reparos, renovação da frota) e da própria força de trabalho" (FONTES, 2017, p.57). Todo o ônus é do trabalhador: os gastos ao comprar e utilizar um veículo (combustível, manutenção, depreciação, seguro), despesas adicionais como pedágios e estacionamentos, a taxa de cobrança da Uber; tudo isso leva a um expressivo número de trabalhadores miseravelmente pagos e com jornadas exaustivas. Ao retomar a discussão sobre a expropriação, Fontes (2017, p.57) afirma que:

[...] os proprietários dessas coisas (no caso, automóveis) são facilmente expropriáveis. O próprio desgaste dos automóveis - sem falar da saúde dos motoristas - fica inteiramente a cargo dos trabalhadores. Imaginando livrar-se desse custo, os motoristas passaram a alugar automóveis. Devem, portanto, pagar o aluguel a outro proprietário da ferramenta automóvel, entregando parcela do mais-valor que produzem e continuando a encaminhar ao Uber a 
parcela pré-fixada como valorização do valor resultante de seu trabalho.

Desta maneira, todas as taxas e riscos são assumidos pelo próprio trabalhador. "A Uber sustenta que a segurança é - como nunca cansam de dizer - a maior prioridade, mas que os motoristas não são empregados da Uber e a Uber não é responsável pelo que acontece na viagem" (SLEE, 2017, p.121). "A classificação como contratante independente livra a companhia de ter de pagar por direitos trabalhistas e de ter de respeitar os padrões de emprego. O risco é inteiramente empurrado para o subcontratado" (SLEE, 2017, p.134).

Assim, as companhias exitosas de Economia do Compartilhamento, como a Uber, escapam das despesas em prover uma folha de pagamento ou manter qualquer custo com seus empregados (para eles, fornecedores de serviços), pois os classificam como autônomos. Da mesma maneira, "como parte desse artifício, evitam pagar direitos trabalhistas, custos de manutenção, tempo ocioso e tempo de deslocamento, acidentes de trabalho e qualquer obrigação de seguridade social" (SLEE, 2017, p.294).

Como se não bastasse, "a Uber obriga os motoristas a aceitarem $90 \%$ de todas as corridas que the cruzem o caminho, sob pena de serem banidos, o que significa que há um preço a ser pago quando se rejeita alguém" (SLEE, 2017, p.125). Isso, somado ao fato de que muitos motoristas destinam longas horas para pagar, inclusive, a compra do carro em que trabalha, torna a ameaça de ser retirado da plataforma algo ainda mais assustador.

A Economia do Compartilhamento - mais destacada no Brasil por meio da Uber -, promete ajudar prioritariamente indivíduos vulneráveis a tomar controle de suas vidas, tornando-os microempresários que podem se auto-gerenciar, entrando e saindo deste novo modelo flexível de trabalho com a ideia de ganhar uma "graninha extra", ou mesmo tendo-o como única renda num momento de desemprego. A Uber manifesta "a enganosa ladainha de que está ao mesmo tempo entregando viagens baratas aos usuários e oportunidades de trabalho bem remuneradas aos motoristas" (SLEE, 2017, p.27).

Além disso, a uberização acaba gerando uma competição ainda maior entre os trabalhadores, pois quem estabelece ou avalia a sua continuidade nesse tipo de trabalho é o cliente, quem paga pelo serviço. A realização do trabalho conta com a disposição do trabalhador em aceitar a tarefa oferecida - o que quer dizer um 
permanente gerenciamento de sua própria produtividade, mas essa aceitação requer vencer a concorrência entre os motoristas disponíveis. A avaliação da multidão de consumidores fornece os elementos para o ranqueamento dos trabalhadores (ABÍLIO, 2017, p. 1).

Ou seja, ao invés de trazer confiança pessoal, triagem ou prover um sistema de reputação, conforme propagandeia a empresa; foi criada uma nova forma de fiscalização e vigilância em que os prestadores de serviços devem viver com o eterno medo e insegurança de serem deletados pelos clientes-usuários. Assim, a certificação sobre o trabalho vem agora da esfera do consumo, por meio de uma "espécie de gerente coletivo que fiscaliza permanentemente o trabalhador. A multidão vigilante [...] é então quem garante de forma dispersa a certificação sobre o trabalho" (ABÍLIO, 2017, p.1).

Assim, os acordos coletivos acabam sendo rebaixados ao plano individual em sua máxima e, obviamente, isso torna ainda mais fracos os trabalhadores diante daqueles que os contratam. Um rebaixamento que "não é só econômico, mas também moral e ético" (POCHMANN, 2016, p.18).

No entanto, não se pode deixar de ressaltar que há inúmeras contradições e importantes lutas contra esse tipo de prática, em especial, contra a empresa Uber, e existem movimentos que vêm denunciando o tipo (ou ausência) de vínculo empregatício. Já estão em ato novas formas de organização política, que envolvem a criação de sindicatos de aplicativos, greves e manifestações de trabalhadores uberizados. Conforme destacou Abílio (2017, p.1):

Em 2016 ocorreu uma série de manifestações, greves, processos judiciais, formação de sindicatos de trabalhadores de aplicativos pelo mundo. Motoristas Uber americanos (atualmente mais de 400 mil) juntaram-se a enfermeiras, trabalhadores do setor hoteleiro, entre outros, na campanha "Fight for US\$15", que demandava o pagamento mínimo de quinze dólares por hora de trabalho. Na Califórnia, a empresa Uber, optou por pagar US\$100 milhões em acordo com dezenas de milhares de trabalhadores (não há dados claros sobre esse número) que acionaram coletivamente a justiça requerendo reconhecimento legal do vínculo empregatício com a empresa. [...]. No final do ano, a justiça inglesa determinou que a Uber reconhecesse o vínculo empregatício com seus motoristas: o processo ainda está em andamento.

Contudo, estes ainda são movimentos minoritários. A ampla maioria dos trabalhadores que "fornecem seus serviços" consente aos abusos trabalhistas a fim de se manter no posto. É a empresa quem define o modo da produção do serviço, o 
valor cobrado dos clientes, o padrão de atendimento, a forma de pagamento e a modalidade de seu recebimento. É ainda ela quem recebe o pagamento e paga o motorista, além de centralizar o acionamento do trabalhador para sua atividade. Além disso, a Uber conta ainda com um sistema disciplinar que aplica penalidades aos trabalhadores que infringirem suas normas de serviço. Conforme destacou Slee (2017, p. 297):

[...] lobistas bem-remunerados estão argumentando, em Washington, que as novas companhias podem regular o comportamento de seus fornecedores de serviço melhor do que os governos, que os algoritmos exercerão seu trabalho de modo cada vez mais responsável e em benefício da sociedade.

No entanto,

[...] muitos motoristas estão convencidos de que o sistema [da plataforma Uber] os engana, por exemplo, mostrando viagens que desaparecem antes que possam aceitá-las, o que faz com que não consigam atingir os níveis de aceitação necessários para ganhar um bônus. Ou manipulando o tempo de espera por um passageiro que ao final cancela, negando o direito à taxa por desistência (SLEE, 2017, p.132).

Aquilo que Thompson (2011) tão magistralmente indicou que acontecia no final do século XVIII na transição para a sociedade industrial - quando os relógios das fábricas eram adiantados pela manhã e atrasados à noite como disfarces para encobrir a opressão e extrair mais tempo de trabalho -, toma novos ares no século $X X I$, inclusive, sendo realizada por aqueles que dizem ver os trabalhadores como "parceiros" e que se colocam como um campo avançado e inovador no mundo do trabalho. Nada de novo sob o sol. Apenas a forma de dominação ganha novos ares, com o uso das novas tecnologias a serviço dessa lógica, pois a expropriação segue em patamares semelhantes.

Em suma, conforme o exposto ao longo desta seção, a uberização é mais uma forma de extração de mais-valia através da exploração baseada em um controle político e ideológico de novo tipo sobre a força de trabalho. São reestruturações que se inserem na própria dinâmica do capitalismo do século XXI por meio da redução dos custos da força de trabalho, ampliação da precarização das profissões e intensificação do trabalho de forma perversa, e que se baseiam na dificuldade da condição de reprodução do trabalhador, fazendo com que se submeta a qualquer forma de ocupação que gere renda para sua subsistência. 


\section{Forma existente de uberização do trabalho docente: o caso da rede pública estadual paulista}

Conforme determina a Constituição Federal (BRASIL, 1988), a contratação de professores deve ser feita por meio de concurso público ou processo seletivo simplificado para atender a necessidade temporária de excepcional interesse público; porém, não é bem isso que vem acontecendo em muitos estados da federação. Fruto de uma política pública que tem privilegiado a contratação temporária como regra em detrimento do concurso público, surgem novos formatos de contrato (ou ausência de um), dentre os quais, destaca-se uma forma de trabalho docente já existente que é a docência eventual.

O professor eventual é aquele cujo vínculo empregatício está aquém da precarização situacional do professor temporário que é admitido por contrato, no qual a investidura no cargo se dá minimamente nos marcos constitucionais, garantindo aos professores ao menos o salário inicial da categoria.

Além da falta de garantia no emprego e da remuneração insegura, os docentes eventuais carecem de uma identidade baseada no trabalho. Quando estão empregados, ocupam empregos desprovidos de carreira e não sentem que pertencem a uma comunidade ocupacional imersa em práticas estáveis, códigos de ética e normas de comportamento.

O trabalho docente que se concretiza no ensino é expropriado brutalmente, afinal o papel desses professores é manter as turmas, realizando atividades previstas num plano de substituição para professores eventuais, configurando uma força de trabalho pronta para ser utilizada na exata medida pelo Estado, ou seja, um trabalho intermitente.

A socióloga Aparecida Neri de Souza afirma que "os professores eventuais não têm aulas e/ou classes atribuídas, mas sim uma vaga em uma escola, para substituírem faltas de professores" (SOUZA, 2012, p.7-8). Eles só são chamados quando tem trabalho e não sabem quanto vão ganhar no final do mês. Como recebem mediante as aulas dadas, não há garantias sequer que sua remuneração atingirá o piso salarial da categoria. 
Há dois tipos de professores eventuais na rede pública paulista: os enquadrados na categoria "S" e os pertencentes à categoria "V"6. Estes docentes "não contam com atribuição de aulas, uma vez que é um professor que substitui um efetivo eventualmente" (Venco, 2019, p.4), configurando segundo a autora, a "pedagogia do improviso" na qual "a convocação feita, em algumas situações, com pouco tempo de antecedência à aula e o não acesso ao planejamento do colega ausente [professor efetivo] resultam em conseqüências tanto para os professores quanto para os alunos" (VENCO, 2019, p. 12).

Os professores eventuais dirigem-se diariamente às escolas, em geral próximas à sua residência, ficam na sala de professores ou na porta das escolas à espera que um ou mais professores faltem. Conforme destaca Aparecida Neri de Souza (2013, p.221):

Por vezes [esses docentes] passam os três turnos (manhã, tarde e noite) na escola para entrar em uma sala de aula e trabalhar. Se não houver falta de professor, não há trabalho. Eles recebem por aula dada, não há pagamento de descanso semanal, férias ou direitos garantidos por contrato de trabalho, mesmo que temporário. Torcem para que um professor peça licença superior a dez dias, porque assim podem ter um contrato temporário.

Diversos trabalhos buscam entender a situação dos docentes eventuais (ARANHA, 2007; BASÍLIO, 2010; GESQUI, 2009; SOUZA, 2012, 2013; SOUZA, 2012; VENCO, 2018, 2019) e todos acolhem o diagnóstico de que a contratação e o exercício das atividades desses professores da rede paulista de ensino público atingem o auge em termos de precarização. Os professores eventuais não possuem vínculo empregatício com o Estado, recebem pagamento somente pelas "aulas efetivamente ministradas, correspondente ao [salário] inicial de sua habilitação, portanto, o valor hora-aula mais baixo pago a cada referência" (SOUZA, 2012, p.78). Eles transformam-se em "não professores", que, devido às características de sua contratação, não podem nem mesmo ser considerados como uma categoria precarizada, pois não têm vínculo, não têm estabilidade, não recebem salário nem exercem uma profissão (SOUZA, 2012).

\footnotetext{
${ }^{6}$ O governo de São Paulo considera as categorias "S" e "V" como professores eventuais. Ambos não contam com atribuição de aulas, uma vez que é um professor que substitui um efetivo eventualmente. A diferença é que a categoria "S" foi admitida em 2007 e pertence ao SPPREV - Regime Próprio de Previdência dos Servidores Públicos (RPPS), estabelecido pela Lei Complementar 1.010/2007 e a categoria "V" foi admitida após julho de 2009, nos termos da Lei Complementar 1.093/2009, com recolhimento ao INSS (VENCO, 2019).
} 
Estes professores devem sempre estar atentos aos editais publicados no site da Diretoria de Ensino Regional (DER) de sua opção - que são colocados com 72 horas de antecedência -, e ao surgirem aulas, caso sua pontuação seja alcançada ao se atender a lista classificatória, ser-lhes-ão atribuídas aulas em alguma escola que Ihes convém. Caso contrário, correm o risco de terem aulas atribuídas compulsoriamente, independente da localização da escola.

Aparecida Neri de Souza $(2012,2013)$ e Elisabeth Souza (2012) caracterizam a situação dos professores eventuais como de "total desprofissionalização", pois, além de eles serem ignorados pelos sindicatos, o próprio governo paulista omite a sua existência nas estatísticas, visto que "não há dados disponíveis sobre a quantidade de professores eventuais" (SOUZA, 2012, p.8) já que não possuem vínculo de emprego. $E$ isso se dá "ao mesmo tempo em que [o governo] publica legislações especificando sua forma de contratação, ou seja, não desconhece sua existência e nem tão pouco a presença constante deste professor nas escolas da rede" (SOUZA, 2012, p.63).

A resolução no 97/2008 da Secretaria de Educação de São Paulo, permite "a atribuição de vagas para admissões em caráter eventual, sem vínculo empregatício, aos candidatos inscritos no processo [de distribuição de aulas anuais]" (SOUZA, 2013). Esses professores:

Candidatam-se anualmente [...] são classificados de acordo com sua experiência no magistério e com seus diplomas. Os de maior pontuação recebem aulas ou classes e são contratados em caráter temporário; aos demais resta o trabalho intermitente ou eventual. Os professores eventuais não têm aulas ou classes, mas sim uma vaga em uma escola para substituir professores. Eles são formados em diferentes campos disciplinares e alguns ainda são estudantes universitários, não sabem em que horários trabalharão nem quantas aulas ministrarão por semana ou por mês, muito menos em que disciplina trabalharão (SOUZA, p.221).

Em linhas gerais, os professores eventuais devem cobrir a falta de um professor responsável por qualquer disciplina (Matemática, Língua Portuguesa, História, Geografia, Educação Física, Artes, Ciências etc.). Ele não sabe previamente qual professor (e qual disciplina) terá que substituir.

Devido à sua condição de eventual (professor esporádico) ele dificilmente constrói vínculo relacional com os alunos, professores ou corpo administrativo das escolas onde atua, além de não construir uma identidade profissional ou se constituir 
enquanto professor de uma disciplina. Ademais, conforme destacam os estudos de Aranha (2007, p.49):

Os professores eventuais atuam em mais de uma escola, migrando de uma escola para outra num intuito de pegar aulas provenientes da ausência de professores titulares de disciplina. Muitas vezes o professor eventual fica com o telefone celular ligado esperando que alguma escola o chame para substituir algum professor.

Deste modo, supõe-se que, o professor eventual, ao ser chamado para ministrar aulas de disciplinas aleatórias, alheias às de sua formação, vivencia uma constante impossibilidade de escolha. Ele está sempre disponível às necessidades do sistema de ensino, torna-se um simples "operacionalizador da aula", "tampando buracos" com o objetivo de manter a máquina funcionando, ou seja, não deixar os alunos, de cujas turmas o docente se ausentou, sem um professor naquele horário.

Esses aspectos concernentes ao professor eventual remetem à necessidade da polivalência ou multifuncionalidade. Aranha (2007) ao referir-se a esses professores, relata situação similar:

[...] um professor eventual, quando não está substituindo um professor responsável por disciplina ausente, aplica seu tempo em fazer serviços bancários para a escola, uma espécie de office boy. Também, não raramente, o eventual se submete a fazer serviços diversos dentro da escola, tirar fotocópias, ajudar a olhar alunos no pátio, acompanhar alunos em passeios, organizar festas na escola ou torneios esportivos etc. (ARANHA, 2007, p.60-61).

Assim o autor detectou uma forma de o professor eventual "agregar atributos positivos para que seu status dentro de uma determinada escola evolua e ele, o eventual, possa aumentar gradativamente a quantidade de aulas ministradas" (ARANHA, 2007, p.60). Deste modo, observa-se que, desde o consentimento para atuar como eventual - muitas vezes com base em agregar atributos para o currículo e somar experiência para pleitear uma vaga no serviço público -, até a aceitação de trabalhos diversos no chão da escola como forma de demandar mais hora-aulas trabalhadas e consequentemente recebidas; são situações que evidenciam um trabalho docente não só precarizado e uberizado, mas despersonalizado e com ausência de sentido.

O professor eventual, conforme exposto, é um trabalhador docente atípico, que tem máxima expressão na rede pública do Estado de São Paulo e configura uma precarização já institucionalizada. Destacamos, a seguir, tendências que seguem uma 
direção parecida (ou piorada) dessa forma de uberização do trabalho docente que surgiram em 2017, não por acaso, o ano em que os direitos trabalhistas foram dizimados no Brasil com a aprovação da Reforma Trabalhista. As iniciativas tratadas a seguir foram levadas pelo poder público e consistiram em inserir novos mecanismos de contratação de docentes na educação básica brasileira, excedendo as condições precárias e de expropriação do trabalho colocadas aos professores eventuais.

\section{Novas tendências de uberização do trabalho docente}

Ao tratar do tema da precarização do mundo do trabalho e relacioná-lo com a educação, Freitas (2016) aborda a "charterização e a uberização" como formas destruidoras de profissões, afirmando que é muito provável que a uberização avance pelas "charters online": escolas que distribuem conteúdos e que usam "tutores" online para apoiar os estudantes em seu estudo, seja quando estão na plataforma de aprendizagem, seja fora dela, sob demanda. Assim,

[...] aos poucos, os processos de precarização vistos em outras profissões vão se aproximando dos professores - inclusive a conversão de seu trabalho vivo em trabalho morto, dentro de plataformas de aprendizagem online que, com ajuda de tecnologia interativa, procura copiar e eternizar a atuação dos profissionais da educação. Trata-se de congelar os processos destinados a apoiar o desenvolvimento das crianças, bem como destinados a regular seu ritmo e profundidade de aquisição de conhecimentos, e registrá-los em códigos informatizados e reprodutíveis sem a presença viva do professor (FREITAS, 2016).

Conforme o previsto na Lei 13.415/2017 (BRASIL, 2017) - que altera a LDB (Lei 9394/96) e institui a Reforma do Ensino Médio -, os sistemas de ensino poderão reconhecer, mediante regulamentação própria, conhecimentos, saberes, habilidades e competências, mediante diferentes formas de comprovação, dentre elas, a educação à distância ou educação presencial mediada por tecnologias. Assim, a LDB (BRASIL, 1996) passa a conter em seu artigo 36, parágrafo 11 que, para efeito de cumprimento das exigências curriculares do Ensino Médio, os sistemas de ensino

\footnotetext{
${ }^{7} \mathrm{O}$ autor, ao discutir as políticas educacionais norte-americanas e traçar alguns paralelos com o Brasil, refere-se às escolas Charters nos Estados Unidos, como um modelo de escola pública que adota a lógica da gestão privada, e que podem ser presenciais ou on-line. Para mais informações sobre o tema ver artigo no Blog do Freitas.
} 
poderão reconhecer competências e firmar convênios com instituições de educação à distância.

Isto, na visão de Freitas (2016), pode abrir caminho para as charters online (empresas que fornecem conteúdo instrucional online). Deste modo, afirma:

A relação professor-aluno que numa sala convencional de aula pode ser de 40 alunos para um professor, pode chegar a 400 alunos para um professor, dez vezes mais, em uma escola online. Se esta forma de organização do trabalho, a uberização, prospera, um professor em sua casa, atende 400 alunos "online". A própria plataforma monitora o tempo gasto pelo professor e gera a base de sua remuneração (FREITAS, 2016).

O autor afirma que, enquanto a "charterização" rompe com a noção de serviço público e o destrói junto com o magistério público, a "uberização" poderá atingir o profissional da educação e remodelar sua relação com a escola (FREITAS, 2016), num processo que, a nosso ver, vem para aumentar a alienação e a expropriação do trabalho do professor.

Além desta reflexão trazida por Freitas, destaca-se também, neste artigo, 0 processo por outro viés, pois assistimos, recentemente, a uberização tentando se inserir na escola pública por meio das relações contratuais. Em Ribeirão Preto ${ }^{8}$, município do interior de São Paulo, o prefeito da cidade, Duarte Nogueira (PSDB), intencionou implementar um Projeto de Lei de Contratação de Professores Substitutos que gerou ampla discussão e resistência entre os profissionais da educação daquele município.

Segundo notícia veiculada no site do Partido da Social Democracia Brasileira (PSDB), em tom de propaganda, o projeto da prefeitura tucana criaria um sistema de trabalho cuja ideia seria:

Pagar por aulas avulsas aos docentes, sem ligação com o município, sempre que faltarem profissionais na rede municipal de ensino. Apelidado de "Uber da Educação" ou "Professor Delivery", a proposta busca resolver o problema da falta de docentes nas escolas (PSDB, 2017, p.1).

Apesar de ter sido divulgado como uma grande ideia inovadora para a educação, no intuito de suprir a falta de professores efetivos, esse projeto se

\footnotetext{
${ }^{8} \mathrm{~A}$ rede municipal de Ribeirão Preto tem 109 escolas da rede direta e outras 24 conveniadas. O sistema tem 3.159 professores, sendo 400 emergenciais, de acordo com dados da própria secretaria. São cerca de 48 mil estudantes matriculados (MOREIRA, 2017).
} 
assemelha muito aos professores eventuais, tratado em seção anterior. As diferenças seriam apenas os meios e instrumentos utilizados para a convocação para o trabalho, que, neste caso, devido à proposta de utilização de novas tecnologias através de uma plataforma, apresenta ares de modernização. Conforme afirmaram:

De acordo com o projeto, o professor não teria vínculo empregatício com a prefeitura e o acionamento se daria por aplicativos, mensagens de celular ou redes sociais. Após receber a chamada, o professor teria 30 minutos para responder se aceita a tarefa e uma hora para chegar à escola. Caso contrário, outro seria acionado em seu lugar (PSDB, 2017, p.1).

Segundo a então Secretaria Municipal de Educação, Suely Vilela, ex-reitora da USP, um dos graves problemas presentes na Rede de ensino de Ribeirão Preto é o absenteísmo docente, ou seja, as faltas pontuais de professores. Buscando solucionar o problema, a secretaria defendeu a importância da medida e propôs o Projeto de Lei Complementar que dispõe sobre o credenciamento de "Professores Substitutos" para ministrarem aulas avulsas surgidas na Rede (CME, 2017, p.1). O projeto, segundo a secretária, foi submetido à consulta da comunidade escolar e estaria em fase de análise das sugestões enviadas à secretaria (MOREIRA, 2017).

De acordo com o Projeto (Art. $1^{\circ} \S 1^{\circ}$ ): "as aulas avulsas são as surgidas exclusivamente por faltas, afastamentos, aposentadorias, demissões, exonerações e serão atribuídas por prazo inferior a 30 dias". Conforme a posição do Conselho Municipal de Educação (CME): "a substituição prevista no projeto de lei consiste para [...] caráter de urgência e de pagamento de acordo com a hora trabalhada, com vínculo 'semilegal'” (CME, 2017, p.2).

Segundo o parecer $n^{\circ}$ 01/2017 (CME, 2017), aprovado em 26 de junho, "a alternativa terá lacunas do ponto de vista qualitativo e criará regime laboral precário". O projeto, portanto, teve parecer contrário do órgão que afirmou que "a aprovação do Projeto de Lei Complementar proposto pela Secretaria Municipal de Educação é desnecessária e descabida. Para o Conselho, tal projeto contém um grave erro pedagógico na solução proposta" (CME, 2017, p.7). Conforme destacam:

A proposta apresenta-se pífia desde o ponto de vista do planejamento, pois não se fundamenta em dados concretos, publicamente apresentados e discutidos, de um problema complexo que requer solucionamento. No tocante à ciência pedagógica, ignora-se todo o acúmulo científico acerca das dificuldades próprias do exercício da 
docência em substituição. Em relação à qualidade da educação, propõe-se solução simplesmente inaceitável do ponto de vista qualitativo, oferecendo, aos alunos, docentes eventuais que, embora se diga atenderão a requisitos mínimos de formação, serão sempre pessoas que a isto recorrerão em razão da situação de absoluto desemprego. Do ponto de vista laboral, cria-se a figura com vínculo extremamente precário no sistema, com potencial para ter seu uso ilicitamente expandido no futuro. Do ponto de vista jurídicoconstitucional, eis que se cria função pública de caráter eventual para atender a necessidade não eventual da Administração (CME, 2017, p.9).

O parecer destaca ainda que "o papel da comissão, da administração municipal e do conselho é descortinar políticas públicas de médio e longo prazo que resolvam tais situações, que não podem ser tratadas como ordinárias" (CME, 2017, p.5). Com as devidas críticas postas, o CME não nega que há um problema a ser resolvido com a falta de professores, e recomenda estudos mais aprofundados antes do envio da matéria à Câmara, caracterizando o projeto em questão como "uma medida voluntarista que [...] não está fundada em dados suficientes e publicamente discutidos" (CME, 2017, p.5).

Apesar de o projeto não ter chegado oficialmente à Câmara da cidade, um grupo de professores distribuiu aos vereadores cópia da proposta preliminar e reivindicou que a ideia fosse barrada, afirmando que o projeto era inconstitucional (MOREIRA, 2017). E, assim, os profissionais da educação daquele município continuaram resistindo e promovendo debates sobre o tema, cuja repercussão tomou proporções nacionais.

Em suma, estas ideias caracterizadas, neste artigo, como tendências (ou ameaças) têm tomado diferentes configurações em diversas redes. São mecanismos escolhidos pelo poder público que garantem aos municípios e aos estados a ausência do vínculo empregatício ou mesmo de um contrato temporário. São maneiras de ficar à margem das regras, ao mesmo tempo em que reivindicam se tratar de grandes inovações para a educação.

São proposições manifestas em projetos de lei, editais e resoluções, que introduzem vínculos extremamente precários nas redes públicas. Destas formas, os docentes só são remunerados se e quando são convocados para atuação esporádica. No fim, são vagas destinadas a quem está desempregado e precisa trabalhar, o que os insere na superpopulação de professores instáveis, constituindo a uberização do trabalho docente. 
Sem tempo de serviço estipulado por meio contratual, tais práticas colidem com o princípio da legalidade, dispostos nos artigos $5^{\circ}$ e $37^{\circ}$ da Constituição Federal (BRASIL, 1988), os quais obrigam a Administração Pública a fazer somente o que está previsto em lei. Portanto, há inconstitucionalidade nas referidas iniciativas. Além disso, contrariam os princípios legais regidos pela LDB 9394/1996 que diz em seu Art. 67 que os sistemas de ensino promoverão a valorização dos profissionais da educação, assegurando-lhes, inclusive nos termos dos estatutos e dos planos de carreira do magistério público:

I - ingresso exclusivamente por concurso público de provas e títulos;

II - aperfeiçoamento profissional continuado, inclusive com licenciamento periódico remunerado para esse fim;

III - piso salarial profissional;

IV - progressão funcional baseada na titulação ou habilitação, e na avaliação do desempenho;

V - período reservado a estudos, planejamento e avaliação, incluído na carga de trabalho;

VI - condições adequadas de trabalho (BRASIL, 1996).

Portanto, os projetos propostos contrariam a LDB, não possuem previsão legal e ferem a isonomia estatutária prevista na Constituição Federal, todavia, surgem e se apresentam sem pudores. Apesar dos impedimentos momentâneos e da resistência efetivada contra todos eles, teme-se que, num contexto de liberação das terceirizações, privatizações e de um duro ajuste fiscal com austeridade, os concursos públicos sejam cada vez menos realizados e que os professores efetivos deem lugar aos prestadores de serviços.

O artigo 170 da Constituição Federal (BRASIL, 1988) explicita a valorização do trabalho humano com o fim de assegurar uma existência digna. Consta-se, no entanto, uma antípoda deste cenário. Os desdobramentos da alienação do trabalho docente, decorrente da reificação sob as relações apresentadas neste texto, têm levado os professores a perderem o controle sobre a própria atividade que desenvolvem, afastando-os precisamente do processo social através do qual se constitui o seu trabalho.

Além disso, é preciso atentar que a tendência latente de uberização do trabalho docente pode vir a aliar o trabalho intermitente com o monitoramento ${ }^{9}$ e o controle,

\footnotetext{
${ }^{9}$ Hoje os docentes já são monitorados ideologicamente pelo Movimento Escola Sem Partido. As denúncias geralmente são feitas pela internet, onde alunos e pais atuam como chefes destemperados que presumem que podem denunciar um professor a qualquer momento, caso considerem que o conteúdo do ensino ministrado seja contrário às suas convicções políticas, morais e religiosas.
} 
fazendo com que os sistemas de reputação se coloquem como um mecanismo de controle mais rígido para estilos disciplinares centralizados, visto que as formas de gerencialismo não são novidades dentro das escolas e das redes públicas de educação.

$\mathrm{Na}$ economia do compartilhamento há uma relação entre fornecedores de serviço e consumidores em que as regras de proteção do consumidor são substituídas por algorítimos e sistemas de classificação (reputação). Esta lógica pode se estender para as demais profissões, inclusive para o ranqueamento de professores que atuam nas redes públicas. Assim os próprios "consumidores do serviço" fiscalizariam as supostas "más condutas" dos professores, completando um quadro de uberização do trabalho docente.

Como no Uber, em que no coração do controle está o sistema de reputação do motorista, que permite aos passageiros classificar os condutores, o mesmo poderia ser atribuído ao trabalho docente. Assim, os professores também poderiam ser avaliados por estas plataformas e, dependendo do resultado de seu desempenho, permaneceria ou não como um candidato ao trabalho.

Desta maneira, a "responsabilização" dos docentes agora seria colocada como tarefa da população em geral por meio do monitoramento, o que coincide com os mecanismos de vigilância e fiscalização muito presentes na "uberização do trabalho", destacada na primeira parte deste artigo. O "gerente coletivo", a "multidão vigilante" (ABÍLIO, 2017) seriam agora os próprios alunos, os pais ou responsáveis e a comunidade em geral, que teriam a função de supervisionar os professores, regulando o absenteísmo e o desempenho docente.

\section{Considerações finais}

A "Uberização" se apresenta como um caminho aparentemente rápido e fácil para conseguir algum tipo de remuneração, dizendo que há lugar para todos e que o trabalhador é gerenciador de si próprio (ele trabalha quando quer e da forma que ele quiser). No entanto, o fato de existir uma empresa que se coloca como mediadora do encontro entre aqueles que fornecem o serviço e aqueles que querem comprar, não muda as relações de trabalho. O gerenciamento permanece nas mãos da classe dominante e a subordinação continua cabendo aos trabalhadores, que neste caso se 
inserem em jornadas extenuantes para terem algum rendimento, arcam com todos os custos advindos do próprio trabalho e no final do mês muitas vezes acabam ganhando menos que um salário mínimo.

Essa lógica que vem assolando o mundo do trabalho e atingindo fortemente um amplo contingente de trabalhadores desempregados tem se estendido para o setor público. A uberização do trabalho docente mostra-se como um futuro possível para as redes públicas em geral, utilizando-se do trabalho intermitente de seus professores de acordo com sua necessidade. Políticas educacionais que vem sendo implementadas como a Base Nacional Comum Curricular (BNCC), a Reforma do Ensino Médio com seus itinerários formativos e o incentivo à educação à distância tentem a agravar a uberização e, consequentemente, a precarização do trabalho docente.

Em tempos em que os professores foram eleitos como inimigos da nação, sob acusação constante de "doutrinação ideológica" é necessário apontar as múltiplas formas e tendências de precarização do trabalho docente. Para tanto, destacou-se neste artigo uma forma que o trabalho docente tem assumido (uberização) que, além de tornar a realidade dos professores brasileiros algo bastante preocupante, nos coloca a tarefa de buscar compreendê-la.

Por certo, a tendência de uberização do trabalho docente não é a única forma de precarização (SILVA, 2017, 2018), no entanto, nos limites deste artigo, foi pertinente fazer esse recorte, pois a tendência de tornar 0 trabalho docente intermitente é algo que está no horizonte das redes públicas e tende a se alastrar nos próximos anos com o crescente corte de verbas e a limitação dos investimentos em educação.

A utilização de um aplicativo, como propôs a prefeitura de Ribeirão Preto se coloca como uma realidade próxima para as redes públicas. Sob a lógica do monitoramento ideológico, o incentivo de autoridades governamentais para que os professores sejam filmados por seus alunos tende a crescer. Assim, a tecnologia não ajudaria só a convocar docentes para o trabalho, mas também a vigiá-los e puni-los.

Por fim, cabe destacar que muitas das iniciativas tratadas aqui não foram materializadas devido aos impedimentos dos meios judiciais e por meio da organização dos trabalhadores da educação junto aos seus sindicatos. No entanto, elas se colocam como tendências muito possíveis de serem implementadas num futuro próximo, caso não haja a necessária contestação de tais medidas. 


\section{Referências}

ABÍLIO, L. C. Uberização do trabalho: subsunção real da viração. Blog da Boitempo, 2017. Disponível em: https://blogdaboitempo.com.br/2017/02/22/uberizacaodotrabalho-subsuncao-real-da-viracao/. Acesso em: 06 jul. 2017.

ARANHA, W. L. A. Professores eventuais nas escolas estaduais paulistas: ajudantes de serviço geral da educação? 2007. 102f. Dissertação (Mestrado) Faculdade de Ciências e Letras, Universidade Estadual Paulista, Araraquara, 2007.

BASÍLIO, J. R. Contratos de trabalho de professores e a construção da condição docente na escola pública paulista (1974-2009). 2010. 122f. Dissertação (Mestrado) - Faculdade de Educação, Universidade Estadual de Campinas, Campinas, 2010.

BRASIL. Lei no 9394/1996, de 20 de dezembro de 1996. Estabelece as diretrizes e bases da educação nacional, 1996.

1988.

Constituição da República Federativa do Brasil. Brasília, DF: Senado,

Lei 13.415, de 16 de fevereiro de 2017, Altera as Leis nos 9.394, de 20 de dezembro de 1996, que estabelece as diretrizes e bases da educação nacional, e 11.494, de 20 de junho 2007, que regulamenta o Fundo de Manutenção e Desenvolvimento da Educação Básica e de Valorização dos Profissionais da Educação, a Consolidação das Leis do Trabalho - CLT, aprovada pelo Decreto-Lei no 5.452, de 10 de maio de 1943, e o Decreto-Lei no 236, de 28 de fevereiro de 1967; revoga a Lei no 11.161, de 5 de agosto de 2005; e institui a Política de Fomento à Implementação de Escolas de Ensino Médio em Tempo Integral, 2017.

CONSELHO MUNICIPAL DE EDUCAÇÃO. Parecer no 01/2017. Projeto de Lei Complementar que dispõe sobre o credenciamento de professores substitutos para ministrarem aulas avulsas surgidas na rede municipal de ensino de Ribeirão Preto, 2017. Disponível em: https://www.ribeiraopreto.sp.gov.br/seducacao/conselho/i15indconselho.php. Acesso em: 18 jul. 2017.

FONTES, V. Formação dos trabalhadores e luta de classes. Trabalho Necessário. Ano 14, n. 25, 2016.

Capitalismo em tempos de uberização: do emprego ao trabalho. Marx e o Marxismo, v. 5, n. 8, jan./jun. 2017.

FREITAS, L. C. Charterização e Uberização: destruindo profissões. Blog do Freitas, 2016.2 Disponível em: https://avaliacaoeducacional.com/2016/12/18/charterizacao-e- uberizacaodestruindoprofissoes/. Acesso em: 05 abr. 2017.

GESQUI, L. C. Formação e condições de professores eventuais atuantes na rede pública estadual. 2009.2 Disponível em: 
http://www.anped.org.br/reunioes/32ra/arquivos/trabalhos/GT08-5344--Int.pdf. Acesso em: 29 nov. 2011.

MOREIRA, R. Prefeitura de Ribeirão Preto planeja criar 'Uber do Professor'. Estadão, 2017.

Disponível

em:

https://www.acidadeon.com/cotidiano/NOT,2,6,1262086,Prefeitura+de+Ribeirao+Pret o+planeja+criar+Uber+do+Professor.aspx. Acesso em: 18 jun 2018.

MOURA, C. B. A precarização do trabalho docente nas escolas estaduais paulistas. 2013. 127f. Dissertação (Mestrado) - Faculdade de Filosofia e Ciências, Universidade Estadual Paulista, Marília, 2013.

PETROLINA/PE (Município). Credenciamento nº 006/2017. Processo administrativo no 267/2017, 2017.

POCHMANN, M. Entrevista. Revista Poli: saúde, educação e trabalho. Ano IX, № 48, Rio de Janeiro. nov./dez. 2016a.

PARTIDO DA SOCIAL DEMOCRACIA BRASILEIRA. Prefeitura tucana cria "Uber da educação". $2017 . \quad$ Disponível em: http://www.psdb.org.br/acompanhe/noticias/prefeituratucana-cria-uber-da-educacao/. Acesso em: 15 jul. 2017.

SALDAÑA, P. Ausência de professor da rede pública chega a 30 dias no ano no Estado de SP. São Paulo: Folha de São Paulo, 2017. Disponível em: https://www1.folha.uol.com.br/educacao/2017/07/1903769-ausencia-deprofessor-darede-publica-chega-a-30-dias-no-ano-no-estado-de-sp.shtml. Acesso em: 26 set.2017.

SILVA, A. M. Tempo e Docência: dilemas, valores e usos na realidade educacional. Jundiaí: Paco Editorial, 2017.

Dimensões da precarização do trabalho docente no século XXI: o precariado professoral e o professorado estável-formal sob a lógica privatista empresarial nas redes públicas brasileiras. Tese (Doutorado em Educação) Faculdade de Educação, Universidade Federal do Rio de Janeiro, Rio de Janeiro, 2018

SLEE, Tom. Uberização: a nova onda do trabalho precarizado. São Paulo: Editora Elefante, 2017.

SOUZA, A. N. A modernização do trabalho de professores: processos de precarização e ataque ao trabalho. In: 36ํㅡㄹ ENCONTRO ANUAL DA ANPOCS. 2012. Anais... Águas de Lindóia/SP, 2012. Disponível em: https://anpocs.com/index.php/papers-36encontro/gt-2/gt08-2/7923-amodernizacao-do-trabalho-de-professores-processo-deprecarizacao-e-ataque-aotrabalho/file>. Acesso em: 23 set. 2017.

Professores, modernização e precarização. In: ANTUNES, Ricardo (Org). Riqueza e Miséria do Trabalho no Brasil II. São Paulo; Boitempo, 2013. (p. 217-227). 
SOUZA, E. P. O papel contraditório do professor eventual da rede pública de ensino do Estado de São Paulo na articulação das relações de trabalho e profissão docente: "Iúmpen-professorado"? Dissertação (Mestrado) - Faculdade de Humanidades e Direito, Universidade Metodista de São Paulo, São Bernardo do Campo, 2012.

INSTITUTO BRASILEIRO DE GEOGRAFIA E ESTATÍSTICA. Pesquisa Nacional por Amostra de Domicílios Contínua. 2019. Disponível em: https://agenciadenoticias.ibge.gov.br/agencia-noticias/2012-agencia-denoticias/noticias/24283-desemprego-sobe-para-12-7-com-13-4-milhoes-de-pessoasem-busca-de-trabalho. Acesso em: 18 jun. 2019.

THOMPSON. E. P. Costumes em comum: estudos sobre a cultura popular tradicional. São Paulo: Companhia das Letras. 2011.

VENCO, S. Situação de quasi-uberização dos docentes paulistas? Revista da ABET, v. 17, n. 1, janeiro a junho de 2018.

Uberização do trabalho: um fenômeno de tipo novo entre os docentes de São Paulo, Brasil? Caderno de Saúde Pública, 35, 2019. 